\title{
Evaluating the Ultra-High Pressure Homogenization (UHPH) and Pasteurization effects on the quality and shelf life of donkey milk
}

\author{
Cephas Nil Akwei Addo ${ }^{a}$ And Victoria Ferraguta ${ }^{a^{*}}$ \\ ${ }^{a}$ Centre Especial de Recerca Planta de Tecnologia dels Aliments (CERPTA), Departament de Ciència Animal \\ i dels Aliments, Facultat de Veterinària, Universitat Autònoma de Barcelona, 08193 Bellaterra (Cerdanyola del \\ Vallès), Barcelona, Spain \\ ${ }^{*}$ Corresponding author \\ victoria.ferragut@uab.cat \\ TEL: +34935813292
}

Received: 9 July 2014; Published online: 18 April 2015

Invited paper from the $3^{\text {rd }}$ International ISEKI_Food Conference - ISEKI_Food 2014 - Bridging Training and Research for Industry and the Wider Community - Food Science and Technology Excellence for a Sustainable Bioeconomy

\begin{abstract}
Donkey milk has functional properties of great interest to human nutrition. The effects of ultra-high pressure homogenization (UHPH) at $100 \mathrm{MPa}, 200 \mathrm{MPa}$ and $300 \mathrm{MPa}$ in comparison with different pasteurization treatments of $70{ }^{\circ} \mathrm{C}$ for $1 \mathrm{~min}$ and $85{ }^{\circ} \mathrm{C}$ for $1 \mathrm{~min}$ on the physicochemical quality and shelf-life of treated and raw (untreated) donkey milk were studied. Gross composition and $\mathrm{pH}$, total mesophilic counts, lysozyme activity and physical stability were studied during storage at $4{ }^{\circ} \mathrm{C}$ for 28 days. The compositional profile showed resemblance to that of human milk characterized by high lactose, low fat and low protein content and was least affected by the treatments. UHPH treatments at $200 \mathrm{MPa}, 300 \mathrm{MPa}$ and $85^{\circ} \mathrm{C}$ were able to maintain steady $\mathrm{pH}$ during storage whereas the low intensity treatments showed a significant decrease. The observed lysozyme activity in the samples was generally high and appeared to have been enhanced by the applied UHPH and pasteurization treatments with no significant change during storage. Although the raw milk showed good initial microbial quality, extensive growth of mesophilic microorganisms occurred after 7 days of storage, unlike the treated samples which were able to maintain significantly low counts throughout the storage period. The physical stability of milk was negatively influenced by the higher UHPH treatments of $200 \mathrm{MPa}$ and $300 \mathrm{MPa}$ which exhibited sedimentation phenomenon, while creaming was insignificant.
\end{abstract}

Keywords: Donkey milk; Lysozyme activity; Microbial inactivation; Physical stability, Ultra-high

\section{Introduction}

Milk from non-ruminant species for human consumption is recently receiving much attention as an alternative to cow milk due to a number of nutritional and health concerns. Milk protein associated with allergies, gut intolerances and hyperlipidemia limit cow milk acceptability for certain groups of individuals including infants, young children, lactating mothers and the elderly (Businco et al., 2000). Donkey milk is proposed to be the best alternate in such situations and has been claimed to be highly digestible (Inglingstad et al., 2010). Donkey milk has been recommended for infants when it is not possible to breast feed and when there is no possibility to use cow milk as 
an alternative due to protein allergies (Monti et al., 2007). Donkey milk chemical composition is very close to human milk, due to its similarity in nutritional composition, and its therapeutic purpose has been known centuries ago for the curing of several diseases (Conte et al., 2004). It is characterized by high lactose and low fat and protein contents. Its lipid fraction is similar to that of human milk and possesses higher amounts of unsaturated: saturated fatty acids, linolenic acid and lower $n-6 / n-3$ ratio. It has low levels of caseins and $\beta$-lactoglobulin. The optimum whey protein: casein ratio makes donkey milk very suitable for use in paediatric dietetics thus receiving increasing research and commercialization (Uniacke-Lowe, Huppertz, \& Fox, 2010).

The presence of lysozyme as an antimicrobial enzyme has become one of the key components of interest in donkey milk. Lysozyme exerts its antibacterial activity against a broad spectrum of bacteria, especially Gram-positives, by hydrolyzing the $\beta$-(1-4)-glycosidic linkages of mucopolysaccharides in bacterial cell walls (Benkerroum, 2008). It is proposed that this function may be beneficial in the intestinal tract by reducing the incidence of gastro-intestinal infections in infants (Businco et al., 2000). Lysozyme has a high resistance to acid and protease; it reaches the gut relatively intact contributing significantly to the intestinal immune response (Tidona et al., 2011). The concentration of lysozyme in donkey milk can reach $4000 \mathrm{mg} / \mathrm{L}$ with only trace amounts in bovine milk (Guo et al., 2007). The milk has been successfully used in feeding infants affected by severe $\mathrm{Ig}-\mathrm{E}$ mediated and non $\mathrm{Ig}-\mathrm{E}$ mediated cow milk protein allergy (CMPA) and has been proposed as an alternative to bovine milk for such children (Carroccio et al., 2000). Monti et al. (2007) showed that $82.6 \%$ of children who were intolerant to any cow milk substitute liked and tolerated donkey milk. Due to the rich nutritional value of donkey milk and its strict seasonal production variability, its processing and preservation is essential. Thermal treatments such as pasteurization and high temperature sterilization are the commonest ways of milk preservation to obtain products of longer shelf life with good microbial quality. However due to the bioactive components contained in donkey milk, the use of highly destructive thermal treatments normally applied to cow milk are probably not suitable if its special functional attributes need to be maintained. Irreversible damage to some functional components in donkey milk by thermal treatments necessary for its sterilization has been detected. Major modification of the nitrogenous profile occurs after heating milk at $90{ }^{\circ} \mathrm{C}$ for $1 \mathrm{~min}$. Fat soluble nutrients, especially $\alpha$-tocopherol content, decrease with increase in temperature and heat processing time (Sorrentino et al., 2005). Although lysozyme is reported to be quite thermally stable, its denaturation was shown to start from temperatures above $70{ }^{\circ} \mathrm{C}$ (Polidori \& Vincenzetti, 2010). In view of this, the use of freeze drying (lyophilization) has been adopted for milk processing by the few commercial donkey milk processing industries available as it seems to be more protective to the sensitive components of the milk and provide an excellent shelf life, usually a year. However, this processing method is very expensive. UHPH is an emerging technology which has shown great potential for processing liquid foods with good microbial inactivating capability (Ferragut, Cruz, Trujillo, Guamis, \& Capellas, 2009). UHPH operates with an applied pressure ranging from 100 to $400 \mathrm{MPa}$. There is an increase in the flow rate and a pressure when liquid food passes through the high pressure valve of the homogenizer creating cavitation, chisel effect, turbulence and collision of the dispersed particles of the food (Floury, Legrand, \& Desrumaux, 2004).

The objective of this study was to explore the response of UHPH technology application in comparison to pasteurization of donkey milk. The effects of those treatments will be studied in terms of microbiological, physical and functional evaluation, and determining the shelf life of treated milks.

\section{Materials and Methods}

\subsection{Sampling and milk treatments}

Fresh donkey milk samples were supplied from a Spanish farm (Fuives del Berguedà). The milk was collected from a herd of 10 lactating donkeys in their first to third month of lactation in 
3 different batches. Foals were separated from their mothers 3 hours before milking. Milking was done manually and the freshly received milk kept at $5{ }^{\circ} \mathrm{C}$ until treatments the next day.

Milk samples were subjected to 2 levels of pasteurization and 3 levels of UHPH treatments alongside untreated (raw) milk. The UHPH conditions were $100 \mathrm{MPa}, 200 \mathrm{MPa}$ and $300 \mathrm{MPa}$ at $40{ }^{\circ} \mathrm{C}$ inlet temperature using a UHPH bench top machine (model FPG11300, Stansted Fluid Power Ltd., Essex, U.K) with a flow rate of $10 \mathrm{~L} \mathrm{~h}^{-1}$. The UHPH system was described by Poliseli-Scopel, Hernandez-Herrero, Guamis, and Ferragut (2012). Briefly, inlet temperature of the product was achieved quickly by using a multi-tubular heat exchanger (Garvía, Barcelona, Spain) located before the machine entrance. The temperature at the homogenization valve was monitored by a sensor (PT100) located just at the exit of high pressure valve. Duration of UHPH treatment was estimated as approximately $0.5 \mathrm{~s}$, the time for the product to pass through the high pressure valve. Samples were collected in sterile bottles in a laminar flow cabin adapted for this purpose and stored in a cold chamber at $4^{\circ} \mathrm{C} \pm 2$. The pasteurization conditions used were $70 \pm 2.0{ }^{\circ} \mathrm{C}, 85 \pm 2.0^{\circ} \mathrm{C}$ for $1 \mathrm{~min}$ using the same UHPH equipment with a bypass of the high pressure valve.

\subsection{Gross composition analysis and $\mathrm{pH}$}

Milk protein was determined by the Kjeldahl method ( $\mathrm{TN} \times \mathrm{6}$ 6.38) (International Dairy Federation, 1993), dry matter was analyzed by the oven drying method International Dairy Federation (1987) and fat content was determined by the Gerber method as reported in International Dairy Federation (1991). Ash content was determined gravimetrically using the method of International Dairy Federation (1964) with sample combustion done at $550{ }^{\circ} \mathrm{C}$ for 6 hours in a muffle furnace (Select-Horn, J.P Selecta, BarcelonaSpain) after prior drying at $101 \pm 0.5{ }^{\circ} \mathrm{C}$ for 2 hours. $\mathrm{pH}$ was measured for the stored samples every 7 days from day 0 to day 28 using a digital $\mathrm{pH}$ meter (pH-Meter GLP 21+, Crison). Lactose content was analyzed using the
Lactose/D-galactose, UV method (Boehringer Mannheim/R-Biopharm AG, Darmstadt, Germany) as follows: $2 \mathrm{~g}$ milk samples were diluted with $20 \mathrm{~mL}$ distilled water $(1: 10)$ in a $100 \mathrm{~mL}$ volumetric flask, acidified with $1 \mathrm{~mL}$ of $3.0 \mathrm{M}$ trichloroacetic acid for protein precipitation, incubated for $10 \mathrm{~min}$ followed by neutralization with $1.0 \mathrm{M} \mathrm{NaOH}$ and the final volume up to the $100 \mathrm{~mL}$ with distilled water. The resulting mixture was filtered and the clear solution used for the analysis following the protocol described in the method. Absorbance of final reaction mixture was measured at $340 \mathrm{~nm}$ by a spectrophotometer (UV2310 spectrophotometer, Dinko Instruments, Barcelona, Spain).

\subsection{Lysozyme activity determination}

Lysozyme activity was performed on samples every 7 days from day 0 to day 28. It was assessed using a commercial kit based on a fluorimetric method (EnzChek Lysozyme Kit, Invitrogen, Carlsbad CA, USA) in a microplate. The method is based on the lytic action of lysozyme on the cell walls of Micrococcus lysodeikticus labelled with fluorescein to such a degree that fluorescence is quenched. Milk samples were diluted 32fold in $1 \mathrm{X}$ reaction buffer based on the lysozyme activity determined in a prior trial. The final reaction mixture in each well contained $50 \mu \mathrm{L}$ of the $50 \mu \mathrm{g} \mathrm{mL}^{-1}$ DQ lysozyme substrate working suspension and $50 \mu \mathrm{L}$ of experimental samples or the standard curve samples. The reaction mixtures were incubated at $37{ }^{\circ} \mathrm{C}$ for 30 minutes protected from light and the lysozyme activity was measured by a fluorescence spectrophotometer microplate reader at $494 \mathrm{~nm}$ excitation and $518 \mathrm{~nm}$ emission (Cary Eclipse Fluorescence Spectrophotometer, Agilent Technologies USA) against sample blanks and expressed as activity units where one unit is defined as the amount of lysozyme required to produce a change of 0.001 absorbance units $\min ^{-1}$ at $450 \mathrm{~nm}$ at $\mathrm{pH} 6.24$ and $25{ }^{\circ} \mathrm{C}$. Sample blanks were prepared in the same way as samples except for replacing the lysozyme substrate working suspension with the reaction buffer. A lysozyme standard curve for each plate was prepared within the range $500 \mathrm{U}$ 
$\mathrm{mL}^{-1}$ to $0 \mathrm{U} \mathrm{mL}^{-1}$.

\subsection{Microbiological analysis}

Total mesophilic bacteria were determined for all samples on plate count agar (PCA) medium (Oxoid Ltd., 96 Basingstoke, Hampshire, U.K). The microbial determinations were performed on day 0 and after every 7 days until day 28. Fresh samples kept at $5{ }^{\circ} \mathrm{C}$ in sterile bottles were taken at each time for the assay. Analysis was done in triplicate and incubation at $30{ }^{\circ} \mathrm{C}$ for 48 hours. Visible colonies were counted and the average calculated.

\subsection{Physical stability determination}

The physical stability was performed on samples for a period of 28 days using the Turbiscan ${ }^{\circledR}$ (TAP, 2009) apparatus (Formulaction, USA). Measurement in this apparatus is based on the scanning of near infrared light $(\lambda=880 \mathrm{~nm})$ from the bottom to top of the sample vial, by measuring the percentage of DeltaH (t) backscattered through the sample at a fixed temperature. Results were expressed by the determination of the height $(\mathrm{mm})$ of solids layer settled and height of creaming layer at the top, at different days during storage. For that purpose, a tool of the software provided by the manufacturer was used.

Each sample was filled into Turbiscan ${ }^{\circledR}$ (TAP, 2009 ) vials with the addition of 3 drops of $0.02 \%$ sodium azide as preservative agent and stored in a cold chamber at $5{ }^{\circ} \mathrm{C}$ during the entire experimental period. Measurements were performed at $20{ }^{\circ} \mathrm{C}$ every week in triplicate.

\subsection{Statistical analysis}

All results presented are means of three individual productions of donkey milk and each sample analysed in triplicates unless otherwise stated. Data were processed by analysis of variance (ANOVA) using the Student's NewmanKeuls method for multiple comparisons of means.
Analysis was performed by SPSS 21.0 statistical packages (IBM, 2012).

\section{Results and Discussion}

\subsection{Milk composition and $\mathrm{pH}$}

The donkey milk composition $(\% \mathrm{w} / \mathrm{w}$ of mean values from raw and the different treated samples) was characterized as follows: $8.7 \pm 0.5$ dry matter; $1.61 \pm 0.08$ total protein; $0.37 \pm 0.04$ fat; $6.6 \pm 0.3$ lactose; $0.49 \pm 0.03$ ash. Thus donkey milk was characterized by a lower dry matter content comparable to dry matter values reported in the literature by Ivanković et al. (2009) and Salimei et al. (2004) who both worked on different donkey breeds. The low average of fat content was consistent to those reported by different authors (Conte, Calabrò, \& Monsù, 2003; Chiofalo, Azzara, Liotta, \& Chiofalo, 2004) although much higher values of $1.68 \%$ have been reported (Pinto, Lestingi, Caputi Jambrenghi, Marsico, \& Vonghia, 1998). The fat content has been reported by Giosue, Alabiso, Russo, Alicata, and Torrisi (2008) to be much influenced by seasonal variability and lactation stage even for the same breed. Protein content was within the average values found in literature reported for donkey milk and consistent to those presented by Coppola et al. (2002) and Ivanković et al. (2009). Less variability in the ash content was observed and its values were similar to those reported by Coppola et al. (2002). The high lactose content was in agreement with that reported by Di Renzo, Altieri, and Genovese (2013). As expected, the various treatments did not significantly affect milk composition. This composition profile represents great similarity to that of human milk as also observed by Coppola et al. (2002) except for the low fat content. Compared to bovine milk, the lactose content is very high whereas the total solids, protein and fat appear to be much lower.

The $\mathrm{pH}$ of raw milk after milking was on average $7.19 \pm 0.1$, similar to $\mathrm{pH} 7.18$ obtained by Salimei et al. (2004) and other authors. As shown in Figure 1, at day 0, raw and treated donkey milk presented similar $\mathrm{pH}$ values. Significant decline in $\mathrm{pH}$ was observed for the raw milk especially 


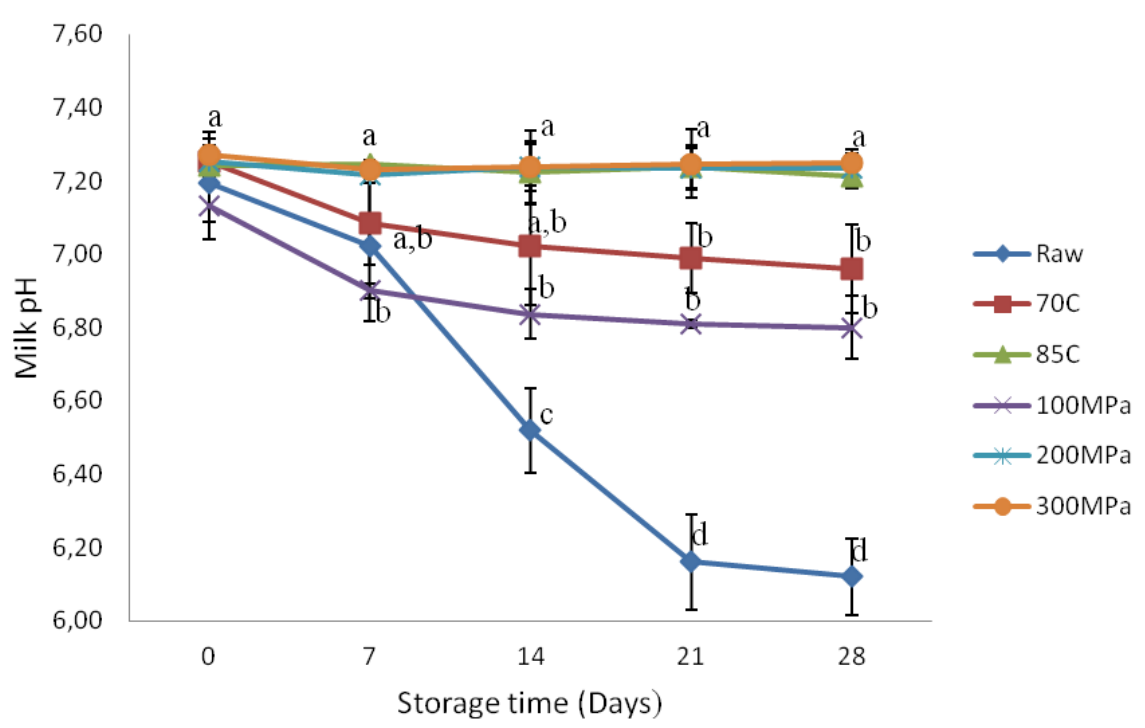

Figure 1: $\mathrm{pH}$ evolution of raw and treated donkey milk samples during 28 days storage at $4{ }^{\circ} \mathrm{C}$. The results represent the means and standard deviations (error bars) of triplicate readings of each sample from 3 individual productions. Different letters on data points indicate significant differences $(P<0.05)$

from day 7 to day 21. The $100 \mathrm{MPa} \mathrm{UHPH}-$ treated sample showed a sharp decline in $\mathrm{pH}$ at day 7 of storage, significantly lower than the other treated samples which, however, remained steady over the entire storage period until day 28. A similar pattern was also exhibited by the $70{ }^{\circ} \mathrm{C}$ pasteurized sample but with a gentle $\mathrm{pH}$ change. The $\mathrm{pH}$ of the higher intensity treatments $85{ }^{\circ} \mathrm{C}, 200 \mathrm{MPa}$ and $300 \mathrm{MPa}$ remained relatively stable during the 28 days of storage with final $\mathrm{pH}$ values around 7.2. After day 14 the $\mathrm{pH}$ of raw, $70{ }^{\circ} \mathrm{C}$ and $100 \mathrm{MPa}$ samples were all significantly lower than those of $85^{\circ} \mathrm{C}, 200$ $\mathrm{MPa}$ and $300 \mathrm{MPa}$. The decline in $\mathrm{pH}$ of milk samples subjected to the mild treatments could be attributed to acidification provoked by microbial growth.

\subsection{Lysozyme activity}

In the lysozyme activity, values measured in all treated samples during storage are presented in Table 1. Similar values were recorded within treatments comparable to the values measured in the raw milk. However, lysozyme activities for those treated samples were slightly higher than the raw milk although not statistically significant. Changes in lysozyme activities during sample storage were monitored and their evolution followed a similar pattern in all samples. A gradual progressive increase in activity was observed from day 0 to day 14 for raw milk and the two pasteurized samples. The UHPH-treated sample at $100 \mathrm{MPa}$ had its highest activity on day 7 . The $200 \mathrm{MPa}$ treated sample showed a steady lysozyme activity during the first fourteen days while the $300 \mathrm{MPa}$ treated sample showed a decrease during the entire period of storage. However, in spite of lysozyme activity variation in the different treated samples and storage periods, loss of activity at day 28 was negligible and statistically similar in all samples.

In donkey milk, the high lysozyme content and activity is an important fact which acts as an antimicrobial natural agent thus constituting an essential component that needs to be preserved even when processed. As with other enzymes, their activity can be easily influenced positively or negatively by technological treatments. However, this experiment showed no significant dif- 
UHPH and Pasteurization effects on donkey milk $\mid 109$

Table 1: Mean ${ }^{a}$ values $\pm \mathrm{SD}$ of lysozyme activity $\left(\mathrm{U} \mathrm{mL}^{-1}\right)$ for raw and treated samples during storage at $4{ }^{\circ} \mathrm{C}$

\begin{tabular}{lccccc}
\hline Treatment & Day 0 & Day 7 & Day 14 & Day 21 & Day 28 \\
\hline Raw & $11531 \pm 923$ & $13689 \pm 3473$ & $15725 \pm 940$ & $10588 \pm 3556$ & $11746 \pm 3719$ \\
$70{ }^{\circ} \mathrm{C}$ & $13761 \pm 3573$ & $17588 \pm 6739$ & $18961 \pm 4297$ & $13556 \pm 2476$ & $10525 \pm 4510$ \\
$85{ }^{\circ} \mathrm{C}$ & $12001 \pm 2619$ & $16806 \pm 6968$ & $22503^{*} \pm 3284$ & $13261 \pm 2466$ & $12087 \pm 196$ \\
$100 \mathrm{MPa}$ & $13328 \pm 3257$ & $16032 \pm 4310$ & $15121 \pm 1609$ & $11936 \pm 1790$ & $10132 \pm 2451$ \\
$200 \mathrm{MPa}$ & $14465 \pm 5783$ & $14238 \pm 3216$ & $14296 \pm 1986$ & $11361 \pm 4207$ & $10891 \pm 4259$ \\
$300 \mathrm{MPa}$ & $16149 \pm 4478$ & $15389 \pm 2948$ & $14479 \pm 1604$ & $11323 \pm 1996$ & $10132 \pm 3958$ \\
\hline
\end{tabular}

${ }^{a}$ Data are means from 3 individual productions

*Represents significant difference at $P<0.05$.

ferences due to treatment effect throughout the storage period except for the $85{ }^{\circ} \mathrm{C}$ sample at day 14 which had a significantly higher lysozyme activity than all the other treatments. The lysozyme activities measured for all samples appeared to be very high compared to previous reported data. Conte, Foti, Malvisi, Giacopello, and Piccinini (2012) reported lysozyme activity values ranging from 5800 to $2740 \mathrm{U} \mathrm{mL}^{-1}$ of sample measured in the fresh milk whereas lysozyme activity levels around 4000-5000 $\mathrm{U} \mathrm{mL}^{-1}$ and sometimes as high as $7000 \mathrm{U} \mathrm{mL}^{-1}$ had been reported (Pilla, Dapra, Zecconi, \& Piccinini, 2010). Any of the treatments applied in this study caused an increase of lysozyme activity, although not significantly different. Lysozyme is generally regarded to be very thermostable and only starts to undergo thermal denaturation at elevated heat treatments (Polidori \& Vincenzetti, 2010). Variability in lysozyme content and activity has been reported for fresh and treated donkey milks and also during frozen storage. Vincenzetti et al. (2011) mentioned that the lysozyme content in fresh milk was higher than that found in the same lyophilized samples. Thermal stability of the donkey milk lysozyme has been demonstrated by other researchers to different extents. Pasteurization at $63{ }^{\circ} \mathrm{C}$ for $30 \mathrm{~min}$ appeared not to have any significant effect on the lysozyme activity on microorganisms (Chiavari, Coloretti, Nanni, Sorrentino, \& Grazia, 2005). Coppola et al. (2002) found that heat treatments at 90 ${ }^{\circ} \mathrm{C}$ for $1 \mathrm{~min}$ did not significantly affect donkey milk lysozyme activity compared to raw milk. However, lysozyme inactivation was produced at $121^{\circ} \mathrm{C}$ for $10 \mathrm{~min}$. The effects of UHPH on the lysozyme activity followed the same trend as observed for the heat treated samples. An enhancement in the lysozyme activity was observed by the UHPH treatments compared to the raw milk samples and this was in agreement with the observations made by Iucci, Patrignani, Vallicelli, Guerzoni, and Lanciotti (2007). They found in cow milk that $100 \mathrm{MPa}$ UHPH treatment caused an increase in lysozyme activity on microorganisms and they suggested a number of hypotheses. It was suggested that molecular modification plays an essential role in the observed increased activity since the molecule activity is due to its three-dimensional structure. So any little change in the native conformation of lysozyme could lead to a better exposition of the active site provoking an increase in activity. The UHPH treatment has been shown by Guerzoni et al. (1999) to induce an increase in the exposure of a protein's hydrophobic regions and this increase of hydrophobicity appeared to be the main cause for the enhanced antimicrobial activity of lysozyme (Bernkop-Schnurch, Krist, Vehabovic, \& Valenta, 1998). Partial denaturation of lysozyme at $80^{\circ} \mathrm{C}$ for 20 min has been demonstrated to exhibit strong antimicrobial activity compared with the native lysozyme (Ibrahim, Higashiguchi, Sugimoto, \& Aoki, 1997).

\subsection{Microbiological analysis}

The initial total bacteria counts for the raw milk sample were $4 \log \mathrm{cfu} \mathrm{mL}^{-1}$ ). This was similar to that reported in raw donkey milk by Ivanković 


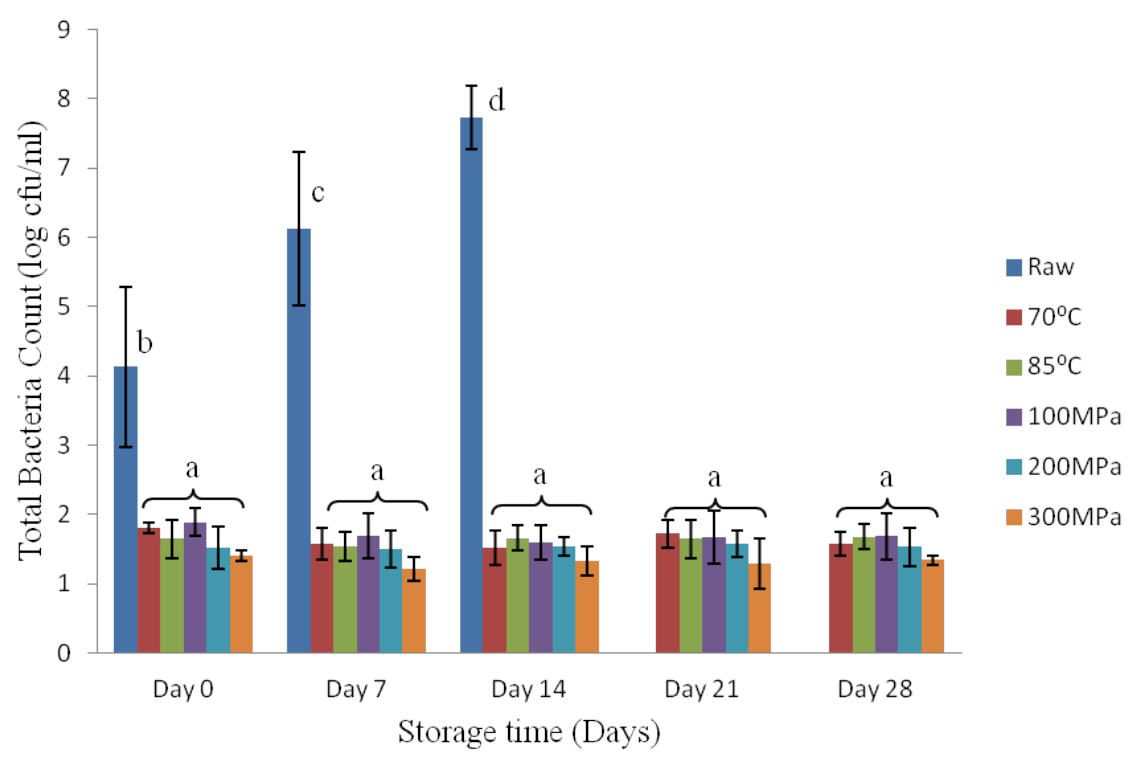

Figure 2: Total bacterial counts for raw and treated donkey milk samples during storage at $4{ }^{\circ} \mathrm{C}$. Results represents the means and standard deviations (error bars) of triplicate readings of each sample from 3 individual productions. a-d: Different letters on bars indicate significant differences $(P<0.05)$

et al. (2009) which was on average lower than the levels found in goat and cow milk. Zhang, Zhao, Jiang, Dong, and Ren (2008) attributed the lower initial microbial counts as a result of the natural antimicrobial agents present in the milk. Much lower microbial counts are associated with raw donkey milks that are machine milked than those manually milked, 3.50 and $4.7 \log \mathrm{cfu} \mathrm{mL}^{-1}$, respectively (Sorrentino et al., 2010). Figure 2 show total microbial counts evolution during storage of raw and treated milks. The microbial counts for the raw milk increased progressively above $6 \log \mathrm{cfu} \mathrm{mL}^{-1}$ after 7 days and much higher at day 14, similar to those observed by Sorrentino et al. (2010) although they reported no significant increase within the first 3 days of storage at $4{ }^{\circ} \mathrm{C}$. There was much variability in the microbial counts for the raw milk among the various batches since the milking was manually done. However, the different treatments applied to milk were able to reduce the microbial counts significantly to below $2 \log$ cfu $\mathrm{mL}^{-1}$, despite the increasing trend observed in raw milk from day 7 . Treated samples, on the other hand, were able to maintain a stable population below $2 \log$ cfu $\mathrm{mL}^{-1}$ over the entire storage period. There were no significant differences in the microbial counts among the various treatments although at $300 \mathrm{MPa}$ samples appeared to be much lower than the others. The mechanisms behind the microbial inactivation by UHPH are not fully understood but have been explained to arise from causes such as increase in temperature generated by adiabatic heating in the machine, spatial pressure and velocity gradients, cavitation, turbulence, solid surface impart and extensional stress (Diels \& Michiels, 2006). The slight decrease in microbial counts for treated samples on day 7 compared to day 0 similarly may indicate the cooperative effect against microbial growth of treatments applied and lysozyme, as also observed by Iucci et al. (2007).

\subsection{Physical stability}

The complex colloidal nature of milk comprising a mixture of fat globules, casein micelles and whey proteins in a continuous water phase makes 
UHPH and Pasteurization effects on donkey milk $\mid 111$

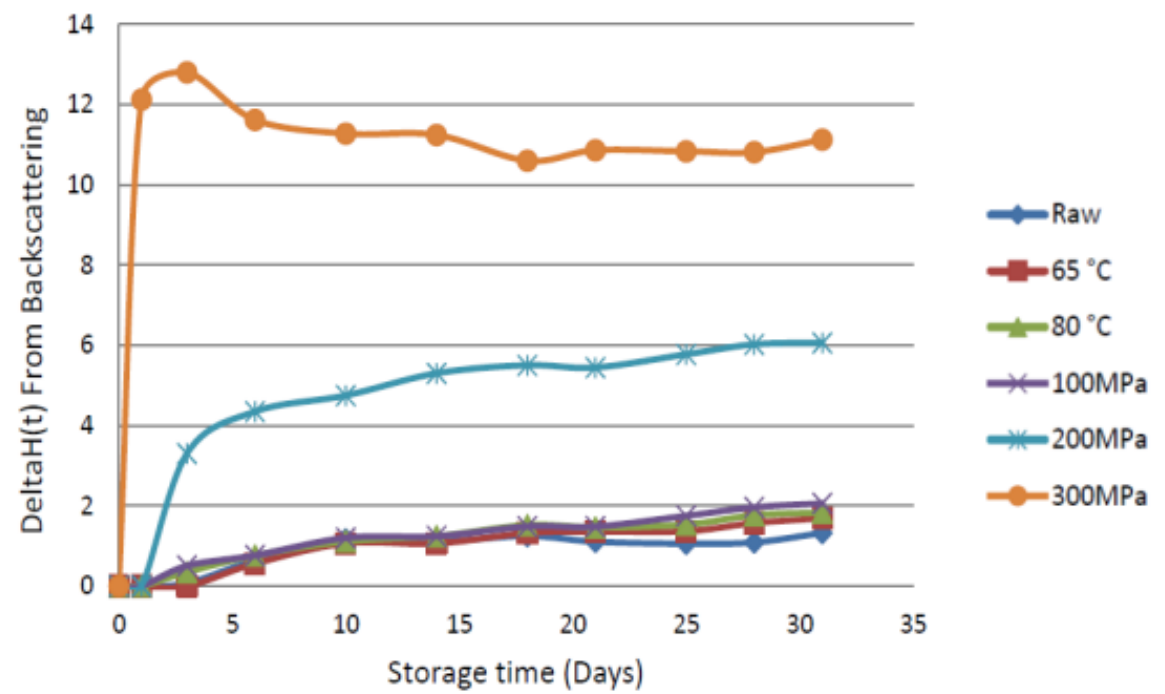

Figure 3: Peak thickness of the sediment layer for raw and treated milk samples during storage at $4{ }^{\circ} \mathrm{C}$

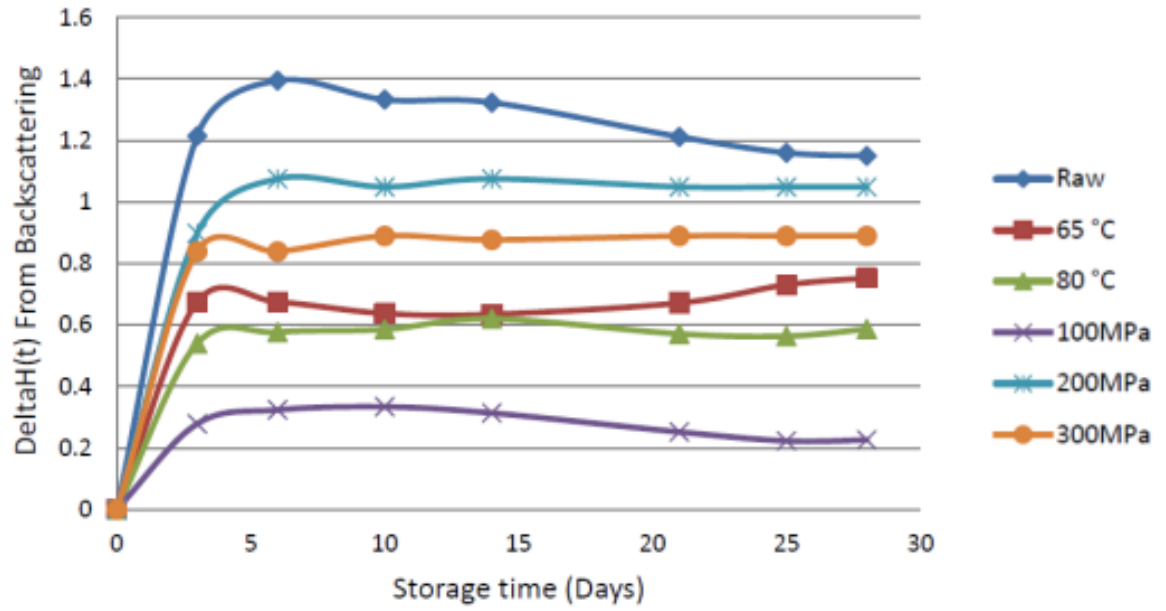

Figure 4: Peak thickness of the cream layer for raw and treated milk samples during storage at $4{ }^{\circ} \mathrm{C}$ 
it stable for only a short period of time. Particle migration produced different destabilization phenomena: sedimentation, aggregation and creaming. The sedimentation phenomenon was observed by the increase in delta backscattering at the bottom of the measurement vial where the sample was placed. This phenomenon was associated with a decrease in backscattering level across the middle portion of the sample which was due to a certain degree of clarification. The creaming phenomenon can be seen from the increase in backscattering on the top of the sample due to migration of lighter fat globules upwards (Durand, Franks, \& Hosken, 2003). The sedimentation and creaming phenomena were computed from the sediment and cream peak thickness as shown in Figures 3 and 4, respectively. From the sedimentation profile in Figure 3 it can be observed that all the samples exhibited a certain extent of sedimentation. The $300 \mathrm{MPa}$ treated sample gave the highest values of sediment formation. It was followed by the 200 $\mathrm{MPa}$ treated milk which exhibited a DeltaH $(\mathrm{t})$ backscatter in the range $4-6 \%$. The profile for the $100 \mathrm{MPa}$ was similar to pasteurised and raw milk profiles with lower DeltaH (t) backscatter $\leq 2 \%$. The increase in sedimentation over the storage period for the raw, pasteurized $(70,85$ ${ }^{\circ} \mathrm{C}$ ) and $100 \mathrm{MPa}$ UHPH treated samples was very gradual from day 0 to day 18 and remained quite stable until day 28 . The $300 \mathrm{MPa}$ sample showed a very sharp increase in sediment formation on day 1 and a much gentler increase to day 3 which decreased gradually afterwards. A similar profile was observed for the $200 \mathrm{MPa}$ sample with the sharp increase in sediment layer from day 0 to day 3 but continuing with a gentle increase to the end of the storage period.

It could be deduced from those observations that the physical instability arising from sediment formation is directly linked to increasing intensity in UHPH treatment and less affected by pasteurization conditions in this experiment. The donkey milk protein fraction is particularly rich in whey proteins. They represent 30-50\% of the nitrogen fraction while in cow's milk it is only 20 \% (Vincenzetti et al., 2011). UHPH treatments of milk in this study were performed at $40{ }^{\circ} \mathrm{C}$ inlet temperature, reaching $113{ }^{\circ} \mathrm{C}$ at the high pressure valve when $300 \mathrm{MPa}$ was applied. This temperature accompanied with the mechanical effects of UHPH may have provoked an intensive degree of whey proteins denaturation, which is a quite thermo sensitive fraction. Protein denaturation to some extent favored protein aggregation which, in turn, led to protein sedimentation. The creaming profile presented in Figure 4 shows the samples to display various degrees of creaming. However, the extent of backscattering was much lower compared to that observed in the sedimentation profile as expected since donkey milk contains very low fat content. The highest creaming was observed for the raw milk since it maintained the fat globule size from the native milk. The $100 \mathrm{MPa}$ treated milk, on the other hand, showed the least creaming among all samples. In this treatment the intensive globule size reduction as a consequence of UHPH application was not accompanied with whey protein denaturation in accordance with the sedimentation results observed, thus the fat globule migration was minimized. In respect to the creaming evolution of samples during storage, all of them remained relatively steady.

\section{Conclusions}

The UHPH treatment of donkey milk was demonstrated to be a processing technology comparable or better than pasteurization in terms of microbiological quality with a shelf-life of 28 days at least. It proved also to have a positive effect on the lysozyme activity similar to pasteurization, maintaining the activity over the storage period. The UHPH effect on physical stability however caused sedimentation in the high intensity UHPH treatments of $200 \mathrm{MPa}$ and $300 \mathrm{MPa}$, so further UHPH combination of pressure and inlet temperature has to be conducted. The potential of donkey milk processed with UHPH treatment in the manufacture of dairy products and its effects on potential protein allergies will be a great follow up to this experiment in enabling a broader exploitation of the technology and donkey milk as a functional food. 


\section{Acknowledgements}

The authors acknowledge Granja Fuives del Berguedà for the milk supply.

\section{References}

Benkerroum, N. (2008). Antimicrobial activity of lysozyme with special relevance to milk. African Journal of Biotechnology, 7(25), 4856-4867.

Bernkop-Schnurch, A., Krist, S., Vehabovic, M., \& Valenta, C. (1998). Synthesis and evaluation of lysozyme derivatives exhibiting an enhanced antimicrobial action. European Journal of Pharmaceutical Sciences, 6(4), 301-306. doi:10.1016/S0928-0987(97) 10026- 4

Businco, L., Giampietro, P. G., Lucenti, P., Lucaroni, F., Pini, C., Di Felice, G., ... Orlandi, M. (2000). Allergenicity of mare's milk in children with cow's milk allergy. Journal of Allergy and Clinical Immunology, 105(5), 1031-1034. doi:10.1067/mai.2000.106377

Carroccio, A., Cavataio, F., Montalto, G., D'Amico, D., Alabrese, L., \& Iacono, G. (2000). Intolerance to hydrolysed cow's milk proteins in infants: clinical characteristics and dietary treatment. Clinical and Experimental Allergy, 30(11), 1597-1603.

Chiavari, C., Coloretti, F., Nanni, M., Sorrentino, E., \& Grazia, L. (2005). Use of donkey's milk for a fermented beverage with lactobacilli. Lait, 85(6), 481-490. doi:10.1051/lait:2005031

Chiofalo, B., Azzara, V., Liotta, L., \& Chiofalo, L. (2004). The chemical and physical parameters of the ragusana ass's milk during lactation. In Proceedings of the 6th national meeting: new findings in equine practice (pp. 77-84). Campobasso.

Conte, F., Calabrò, A., \& Monsù, G. (2003). Il latte di asina: alimento per il futuro. Il progresso veterinario, 2, 63-68.

Conte, F., Scatassa, M., Monsù, G., Verde, V. L., Finocchiaro, A., \& De Fino, M. (2004). Monitoring of safety and quality of donkey's milk. In Proceedings of the international conference on veterinary public health and food safety toward a risk based chain control (pp. 58-59). Roma.

Conte, F., Foti, M., Malvisi, M., Giacopello, C., \& Piccinini, R. (2012). Valutazione dell'azione antibatterica del lisozima del latte d'asina: considerazioni igienicosanitarie. Large animals review, 18(1), 13-16. Retrieved from http://hdl.handle. net $/ 2434 / 220336$

Coppola, R., Salimei, E., Succi, M., Sorrentino, E., Nanni, M., Ranieri, P., ... Grazia, L. (2002). Behaviour of lactobacillus rhamnosus strains in ass's milk. Annals of Microbiology, 52(1), 55-60.

Di Renzo, G. C., Altieri, G., \& Genovese, F. (2013). Donkey milk powder production and properties compared to other milk powders. Dairy Science \& Technology, 93(4-5, SI), 551-564. IDF/INRA 5th International Symposium on Spray Dried Dairy Products (SDDP), Saint Malo, FRANCE, JUN 19-21, 2012. doi:10.1007/s13594-0130108-7

Diels, A. M. J. \& Michiels, C. W. (2006). High-pressure homogenization as a nonthermal technique for the inactivation of microorganisms. Critical Reviews in $\mathrm{Mi}$ crobiology, 32(4), 201-216. doi:10.1080/ 10408410601023516

Durand, A., Franks, G. V., \& Hosken, R. W. (2003). Particle sizes and stability of uht bovine, cereal and grain milks. Food $\mathrm{Hy}$ drocolloids, 17(5), 671-678. doi:10.1016/ S0268-005X(03)00012-2

Ferragut, V., Cruz, N. S., Trujillo, A., Guamis, B., \& Capellas, M. (2009). Physical characteristics during storage of soy yogurt made from ultra-high pressure homogenized soymilk. Journal of Food Engineering, 92(1), 63-69. doi:10.1016/j.jfoodeng. 2008.10.026

Floury, J., Legrand, J., \& Desrumaux, A. (2004). Analysis of a new type of high pressure homogeniser. part b. study of droplet breakup and recoalescence phenomena. Chemical Engineering Science, 59(6), 1285-1294. doi:10.1016/j.ces.2003.11.025

Giosue, C., Alabiso, M., Russo, G., Alicata, M. L., \& Torrisi, C. (2008). Jennet milk production during the lactation in a sicil- 
ian farming system. Animal, 2(10), 14911495. doi:10.1017/S1751731108002231

Guerzoni, M. E., Vannini, L., Lopez, C. C., Lanciotti, R., Suzzi, G., \& Gianotti, A. (1999). Effect of high pressure homogenization on microbial and chemico-physical characteristics of goat cheeses. Journal of Dairy Science, 82(5), 851-862.

Guo, H. Y., Pang, K., Zhang, X. Y., Zhao, L., Chen, S. W., Dong, M. L., \& Ren, F. Z. (2007). Composition, physiochemical properties, nitrogen fraction distribution, and amino acid profile of donkey milk. Journal of Dairy Science, 90(4), 1635-1643. doi:10. 3168/jds.2006-600

IBM. (2012). Corporation released 2012. IBM SPSS Statistics for Windows version 21.0. Armonk, NY: IBM corp.

Ibrahim, H. R., Higashiguchi, S., Sugimoto, Y., \& Aoki, T. (1997). Role of divalent cations in the novel bactericidal activity of the partially unfolded lysozyme. Journal of Agricultural and Food Chemistry, 45(1), 89-94. doi:10.1021/jf9604899

Inglingstad, R. A., Devold, T. G., Eriksen, E. K., Holm, H., Jacobsen, M., Liland, K. H., ... Vegarud, G. E. (2010). Comparison of the digestion of caseins and whey proteins in equine, bovine, caprine and human milks by human gastrointestinal enzymes. Dairy Science 83 Technology, 90(5), 549563. doi:10.1051/dst/2010018

International Dairy Federation. (1964). Determination of the ash content of milk and processed cheese products. FIL-IDF Standard, 27. International Dairy Federation, Brussels.

International Dairy Federation. (1987). Milk, cream and evaporated milk; total solids content. FIL-IDF Standard, 21B. International Dairy Federation, Brussels, Belgium.

International Dairy Federation. (1991). Milk and milk products; fat content. general guidance on the use of butyrometric methods. FIL-IDF Standard, 52. International Dairy Federation, Brussels.

International Dairy Federation. (1993). Milk determination of the total nitrogen content. FIL-IDF Standard, 20B. International Dairy Federation, Brussels.
Iucci, L., Patrignani, F., Vallicelli, M., Guerzoni, M. E., \& Lanciotti, R. (2007). Effects of high pressure homogenization on the activity of lysozyme and lactoferrin against listeria monocytogenes. Food Control, 18(5), 558-565. doi:10.1016/j.foodcont.2006.01. 005

Ivanković, A., Ramljak, J., Štulina, I., Antunac, N., Bašić, I., Kelava, N., \& Konjačić, M. (2009). Characteristics of the lactation, chemical composition and milk hygiene quality of the littoral-dinaric ass. $\mathrm{Ml}$ jekarstvo, 59(2), 107-113.

Monti, G., Bertino, E., Muratore, M. C., Coscia, A., Cresi, F., Silvestro, L., ... Conti, A. (2007). Efficacy of donkey's milk in treating highly problematic cow's milk allergic children: an in vivo and in vitro study. Pediatric Allergy and Immunology, 18(3), 258264. doi:10.1111/j.1399-3038.2006.00521.x

Pilla, R., Dapra, V., Zecconi, A., \& Piccinini, R. (2010). Hygienic and health characteristics of donkey milk during a follow-up study. Journal of Dairy Research, 77(4), 392-397. doi:10.1017/S0022029910000221

Pinto, F., Lestingi, A., Caputi Jambrenghi, A., Marsico, G., \& Vonghia, G. (1998). Conservazione e valorizzazione dell'asino di martina franca: influenza dell'integrazione alimentare su alcuni aspetti quanti-qualitativi del latte. i. alghero, sassari, italy: indagine preliminare. In Proceedings of the 4th congress on biodiversity (pp. 1173-1176). Sassari.

Polidori, P. \& Vincenzetti, S. (2010). Differences of protein fractions among fresh, frozen and powdered donkey milk. Recent patents on food, nutrition \& agriculture, 2(1), 56-60.

Poliseli-Scopel, F. H., Hernandez-Herrero, M., Guamis, B., \& Ferragut, V. (2012). Comparison of ultra high pressure homogenization and conventional thermal treatments on the microbiological, physical and chemical quality of soymilk. LWT-Food Science and Technology, 46(1), 42-48. doi:10.1016/ j.lwt.2011.11.004

Salimei, E., Fantuz, F., Coppola, R., Chiofalo, B., Polidori, P., \& Varisco, G. (2004). Composition and characteristics of ass's milk. An- 
imal Research, 53(1), 67-78. doi:10.1051/ animres:2003049

Sorrentino, E., Di Renzo, T., Succi, M., Reale, A., Tremonte, P., Coppola, R., ... Colavita, G. (2010). Microbiological characteristics of raw ass's milk: manual vs. machine milking. In 61st annual meeting of the european association for animal production (p. 44). book of abstract n16. Wageningen, The Netherlands: Wageningen Academic Publishers.

Sorrentino, E., Salimei, E., Succi, M., Gammariello, D., Di Criscio, T., Panfili, G., \& Coppola, R. (2005). Heat treatment of ass's milk, a hypoallergenic food for infancy. Technological innovation and enhancement of marginal products, 569-574.

TAP. (2009). Turbiscan Application paper. Food: Stability of various beverage emulsions. Formulaction 1-7. Retrieved from http : / / www - titanex . com . tw / doc / tecsupport / ANF- Turbiscan-application \% 20paper \% 20on \% $20 \%$ 20beverage \% 20emulsions.pdf

Tidona, F., Sekse, C., Criscione, A., Jacobsen, M., Bordonaro, S., Marletta, D., \& Vegarud, G. E. (2011). Antimicrobial effect of donkeys' milk digested in vitro with human gastrointestinal enzymes. International Dairy Journal, 21 (3), 158-165. doi:10.1016/j.idairyj.2010.10.008

Uniacke-Lowe, T., Huppertz, T., \& Fox, P. F. (2010). Equine milk proteins: chemistry, structure and nutritional significance. International Dairy Journal, 20(9, SI), 609629. 6th NIZO Dairy Conference, Papendal, NETHERLANDS, SEP 30-OCT 02, 2009. doi:10.1016/j.idairyj.2010.02.007

Vincenzetti, S., Savini, M., Cecchini, C., Micozzi, D., Carpi, F., Vita, A., \& Polidori, P. (2011). Effects of lyophilization and use of probiotics on donkey's milk nutritional characteristics. International Journal of Food Engineering, 7(5). doi:10.2202/ 1556-3758.2032

Zhang, X.-Y., Zhao, L., Jiang, L., Dong, M.-L., \& Ren, F.-Z. (2008). The antimicrobial activity of donkey milk and its microflora changes during storage. Food Control,
19(12), 1191-1195. doi:10.1016/j.foodcont. 2008.01.005 